\title{
Research
}

\section{Resilience Lost: Intersecting Land Use and Landscape Dynamics in the Prehistoric Southwestern United States}

\author{
$\underline{\text { Matthew A. Peeples }}^{1}, \underline{\text { C. Michael Barton }}^{1,2}$, and Steven Schmich ${ }^{1}$
}

\begin{abstract}
The interdisciplinary framework known as resilience theory used by ecologists, social scientists, as well as policy makers, is primarily concerned with the sources of transformation and stability in complex socioecological systems. The laboratory of the long and diverse archaeological record is uniquely suited to testing some of the implications of this theoretical perspective. In this paper, we consider the history of land use and landscape change across the transition from foraging to agricultural subsistence economies in the Middle Chevelon Creek region of northern Arizona. Through this discussion, we highlight the potential roles of diversity and flexibility at multiple spatial and temporal scales in the resilience of human land use practices from the prehistoric past. Expressing the long-term history of this region in a more general theoretical language that bridges the social and natural sciences promotes the collaboration of scientists with expertise deriving from different traditional disciplines. Such a broad perspective is necessary to characterize changes and stabilities in complex socioecological systems.
\end{abstract}

Key Words: adaptive cycle; agriculture; archaeology; human environmental impacts; land use; landscape dynamics; resilience theory; southwestern United States.

\section{INTRODUCTION}

Recently, there has been an increased awareness of the potential role of the historical sciences in considerations of the dynamic nature of past and present socioecological systems (Hardesty and Fowler 2000, van der Leeuw and Redman 2002, Redman and Kinzig 2003, Redman 2005). Documentary reconstructions of human environmental interaction, however, are usually limited to the last few centuries at best. The incorporation of archaeological data into such studies has the potential to greatly increase their time depth, allowing for consideration of cycles of change that occur over hundreds or even thousands of years. In addition to this, studying prehistoric landscape modification and use demonstrates the legacies of past land use practices and their impact on modern landscapes and land use (see van Andel and Zanagger 1990, Butzer 1996, Sandor et al. 1990, Foster et al. 2003).

This paper is an examination of the long-term history of landscape modification and environmental change in one region of the upland American
Southwest. Archaeological data from recent surveys and excavation in the middle Chevelon Creek region of northern Arizona provides a case study to examine the reorganization of the land use practices across the transition from foraging to agricultural subsistence economies. Some of the important consequences of this shift in subsistence include changes in social organization, the intensity of human landscape modification, and social responses to human and natural environmental change. We use this case study to explore these changes in light of the developing interdisciplinary conceptual framework known as "resilience theory" (Holling 1973, Redman and Kinzig 2003, Redman 2005).

The following discussion is divided into three major sections. First, we summarize the general framework of "resilience theory" (RT). Next, we present the analysis of the middle Chevelon Creek archaeological data in light of the concepts of this general framework. Finally, we critically assess the potential of RT for future archaeological research, and more generally for examinations coupled social and ecological change. We argue that RT fits well 
with many traditional archaeological conceptualizations of complex socioecological systems, including the emphasis on diversity and the focus on multiple temporal and spatial scales of analysis. By placing archaeological arguments within the general framework of RT, archaeologists have an opportunity to reach a broader audience within the natural and social sciences and foster the development of new theoretical models. In this respect, RT is perhaps most valuable for archaeology as a way of structuring descriptions of dynamics in complex systems.

\section{RESILIENCE THEORY AND THE ADAPTIVE CYCLE}

Though similar ideas have been presented by others (e.g., Braudel 1980, Butzer 1982), C. S. Holling (1973) is generally credited with first explicitly outlining the perspective now widely known as resilience theory (RT). To proponents of Holling's version of RT, ecological resilience refers to the ability of an adaptive system to undergo change and reorganization while maintaining its fundamental functions, processes, and structures (Holling 1973, Gunderson 2000, Walker et al. 2004). This contrasts with the engineering concept of resilience, which is the ability of a system to quickly return to equilibrium after a disturbance. RT seeks to characterize the processes through which systems change and the sorts of changes that can fundamentally transform adaptive systems (Holling et al. 2002a). In the sciences, the term theory generally suggests a set of explanatory principles for some real-world phenomena. However, resilience theory, as commonly portrayed, is more a guiding perspective for understanding complex adaptive systems than it is an explanatory theory. That is, although RT presents a comprehensive framework for the temporal, organizational, and to a lesser degree spatial distribution of change in ecosystems, it does not offer an equally compelling explanation of why change might occur in this way, although some researchers have offered additional explanation to this end (e.g., Redman and Kinzig 2003).

Using the ecological resilience concept, RT posits that there is usually no single equilibrium for complex socioecological systems but rather multiple potentially stable states. This perspective explicitly recognizes that neither change nor stability in socioecological systems is the norm.
Systems are seen as moving through various stages of an adaptive cycle, which necessarily involves both change and stability at different temporal and spatial scales (Gunderson and Holling 2002, Redman 2005). This adaptive cycle is most often represented schematically as a figure eight divided into four major phases: exploitation (r), conservation $(\mathrm{K})$, release $(\Omega)$, and reorganization $(\alpha)$ (Fig. 1. and Holling and Gunderson 2002).

The four phases of the adaptive cycle can be profitably explored through a comparison with the traditional, three-phase model of ecosystem succession (Holling and Gunderson 2002, Redman and Kinzig 2003). The traditional succession model begins with the $\Omega$-phase, representing the release of accumulated biomass due to external perturbations, i.e., fire, flood, etc. This is followed by the $\mathrm{r}$ phase, representing the exploitation or colonization of recently disturbed areas by rapidly growing and reproducing plants and animals, i.e., $\mathrm{R}$ strategists. The $\mathrm{K}$ phase represents conservation, the slow accumulation of biomass as more slowly growing and reproducing plants and animals, i.e., $\mathrm{K}$ strategists, replace the initial colonizers. The traditional succession model ends here with the development of a "climax community," which eventually may be subject to disturbance and release to start the succession process again. The adaptive cycle adds a key, fourth step. The $\alpha$ or reorganization phase emphasizes that succession will not necessarily lead to a predestined climax community. In the $\alpha$-phase, resources are reorganized or transformed, potentially in novel ways, creating a new system that may or may not differ fundamentally from its predecessors (Holling and Gunderson 2002). Thus, RT explicitly recognizes that there may be multiple, potentially stable equilibrium states, or dynamic equilibria, into which an ecosystem can reorganize following perturbation (Gunderson 2000, Gunderson and Holling 2002, Walker et al. 2004). Importantly, RT also acknowledges that events or processes triggering a $\Omega$ release may include those internal to the system rather than external perturbations (Redman and Kinzig 2003).

Along with the four phases of the adaptive cycle, there are two additional features of adaptive systems that many resilience theorists attempt to characterize. The first is the variable potential of resources for use or transformation, represented by the vertical axis of the adaptive cycle diagram. This axis emphasizes the notion that the distribution and 
Fig. 1. Stylized adaptive cycle diagram. Redrawn from Gunderson and Holling (2002).

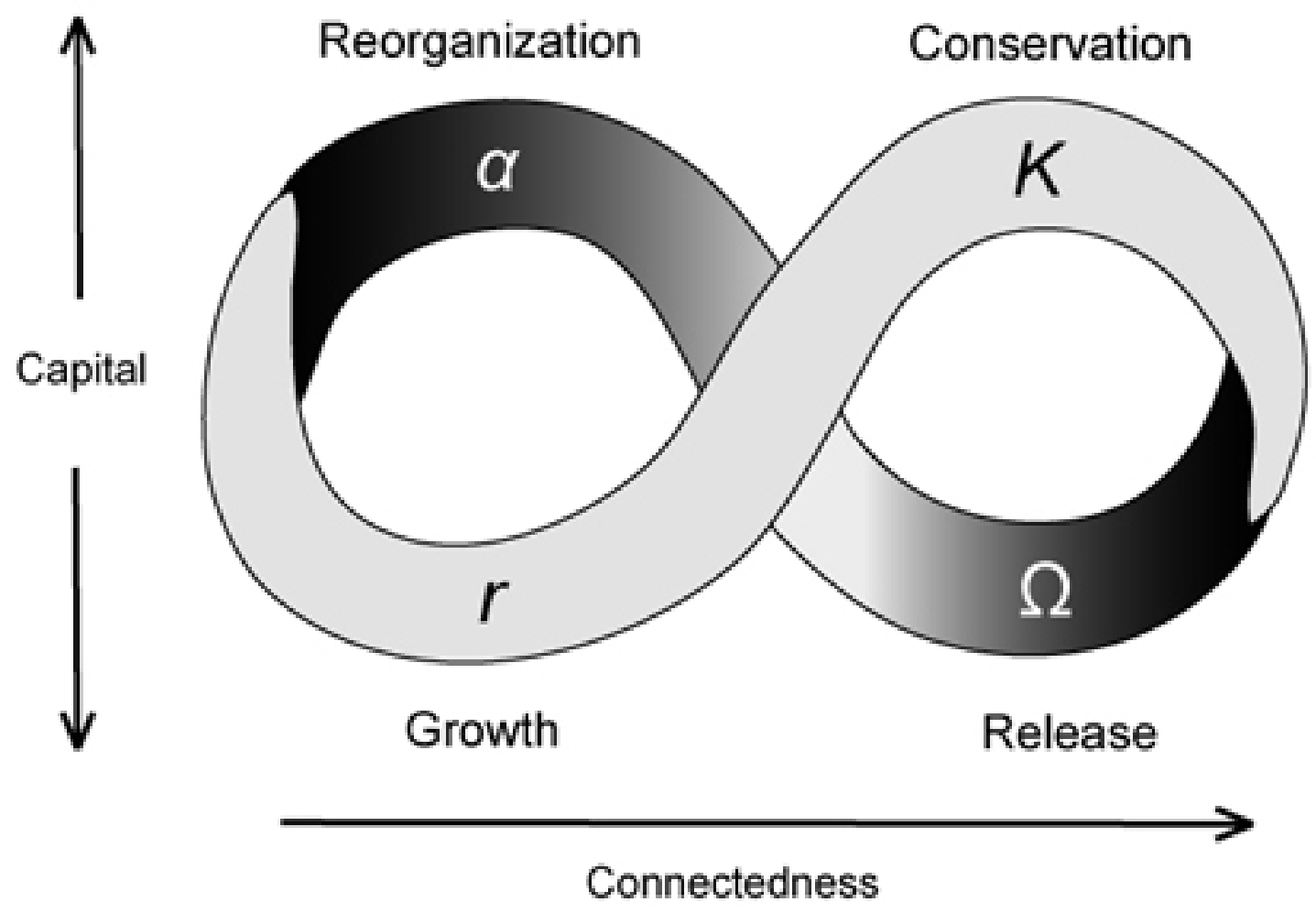

availability of potential resources, i.e., biomass, social capital, etc., differs at different phases within an adaptive cycle. The second feature is the connectedness of a system, represented by the horizontal axis in the adaptive cycle diagram. Connectedness refers to the strength of the relationships between different elements within an adaptive cycle. In other words, how much changes in one aspect of an adaptive system affects other aspects of the system. RT suggests that as systems increase in connectedness, they become less resilient. According to some resilience theorists, changes in one part of an "over-connected" system may initiate a cascade of other changes that fundamentally alter the properties of the entire system. A system with lower connectedness, on the other hand, may be able to absorb changes in one component without fundamentally changing the system as a whole (Holling and Gunderson 2002).

RT encourages the examination of change and adaptation at a variety of spatial and temporal scales; the processes involved in the adaptive cycle at one scale have the potential to propagate across other scales. Resilience theorists have further suggested that the interaction between changes at different scales, i.e., large, small, slow, or fast, may be fundamentally controlled at only a few levels (Holling et al. 2002b). For example, prehistoric farmers may have independently chosen to farm in specific areas, but these decisions were constrained to some degree by the slower cycles of change affecting the locations of arable soil and water, the genetic characteristics of domesticates, and global 
temperature regimes. Reorganization of smaller scale adaptive processes may also propagate and amplify upward, with ultimate system-wide consequences. For instance, Redman (2005) notes that the refusal of a number of individual villages to pay taxes and tribute to a central authority eventually may lead to a lack of resources within the political leadership, culminating in a major transformations in political organization. RT characterizes such cross-scale effects as adaptive cycles that are nested at a number of spatiotemporal scales rather than purely hierarchically organized. The interplay between changes at different scales is referred to collectively as "panarchy" (Holling et al. 2002b, see also Butzer 1982).

The preceding review is by no means complete, as researchers have used resilience theory and the adaptive cycle in a numerous contexts. In the following section, aspects of the adaptive cycle metaphor and the concept of cross-scale interaction will be used as an organizational framework in an analysis of prehistoric land use dynamics in the middle Chevelon Creek region.

\section{LONG-TERM LAND USE ALONG THE MIDDLE CHEVELON DRAINAGE}

The Chevelon Creek drainage of northern Arizona provides an excellent context in which to study the long-term dynamics of human use and modification of upland arid landscapes (Fig. 2). Chevelon Creek flows north from the Mogollon Rim through the ecotonal zones of the Colorado Plateaus' southern margins. Prehistoric occupation in the region extends at least as far back as approximately 9,000 B.C., with discontinuous use and habitation on the lands along middle Chevelon Creek through the early Pueblo IV period, i.e., ca., A.D. 1300. This study is an attempt to reconstruct the changes in the land use practices of prehistoric inhabitants of the region occurring across the transition from foraging to early agricultural subsistence economies.

This analysis is based on a series of recent pedestrian surveys and excavations conducted by Arizona State University archaeologists as part of the Mogollon Rim Small-site Survey (Barton et al., unpublished manuscript, Schmich et al. unpublished manuscript). Beginning in 1997, a number of small lithic sites initially recorded in the 1970s during the Chevelon Archaeological Research Project (Plog et al. 1976) were relocated and rerecorded. Subsequent field seasons included auger test coring and excavation at two of these sites, Chevelon Crossing and Gramma Draw. Additional patch-based field surveys (see below) were conducted in the catchments surrounding both sites. In the following discussion, we focus on the results of the survey and excavation program in the Chevelon Crossing area.

\section{METHODS}

The Chevelon Crossing study area was defined as the potential subsistence catchment around a known occupation site of late Holocene forager groups (Fig. 3). Conceptually, the catchment around the Chevelon Crossing site was defined as the area in which a human forager could collect wild resources or farm, and return in one day, a radius of about 5 km over level ground (e.g., Stone 1996, Varien 1999). The energy needed to walk $5 \mathrm{~km}$ over level ground was used to define a buffered cost surface in a GIS, in which walking energy costs were weighted by slope calculated from a $30 \mathrm{~m}$ resolution digital elevation model (DEM) (see Hill 1995).

Within the catchment, a series of radiating transects were randomly selected within several ecologically based sampling strata to ensure sampling in each of several vegetation communities. These transects were surveyed on foot, with archaeological and ecological data recorded in $50 \times 30 \mathrm{~m}$ patches along each transect and with artifact collections made in $50 \%$, i.e., every other, of the data-recording patches. Unlike most archaeological surveys, data collection units were defined geographically rather than as areas within archaeological sites, whose boundaries are normally defined subjectively by changes in the density of artifacts or by the presence of structures. An important rationale for using a patch-based survey is that it leads to a view of the archaeological record as part of a more inclusive, socioecological landscape that accumulates differentially across space and time (see Barton et al. 2004). This patchbased method also serves to better identify relationships between variation in artifact accumulations, i.e., evidence of past human behavior, and other landscape components.

\section{RESULTS AND DISCUSSION}

Analysis of the survey data revealed that artifact density varied greatly over each transect. However, this variation was structured as patterned 
Fig. 2. Study area of the Mogollon Rim Small-site Survey in northern Arizona.

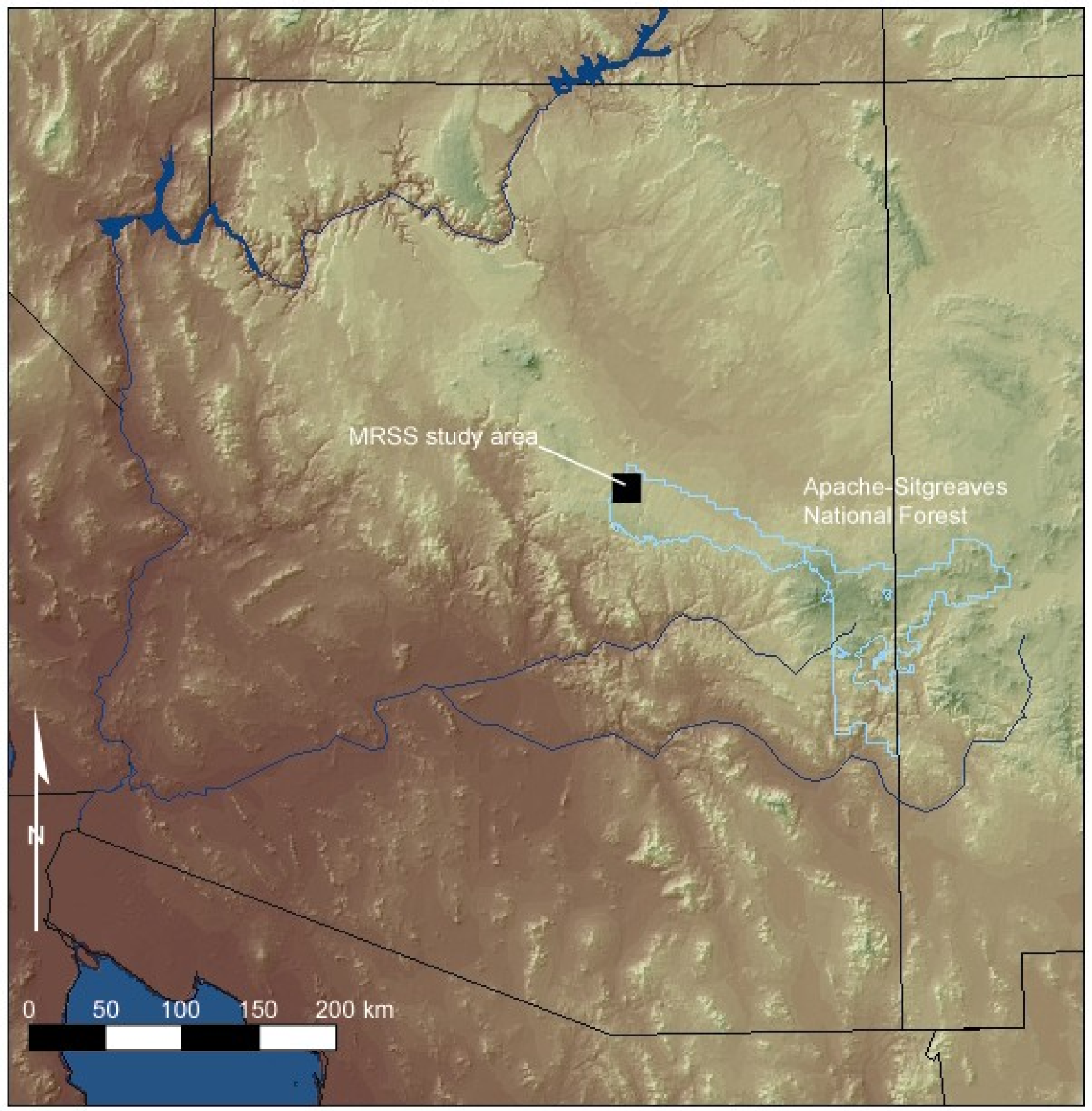


Fig. 3. The Chevelon Crossing study area showing transect units and individual survey patches.

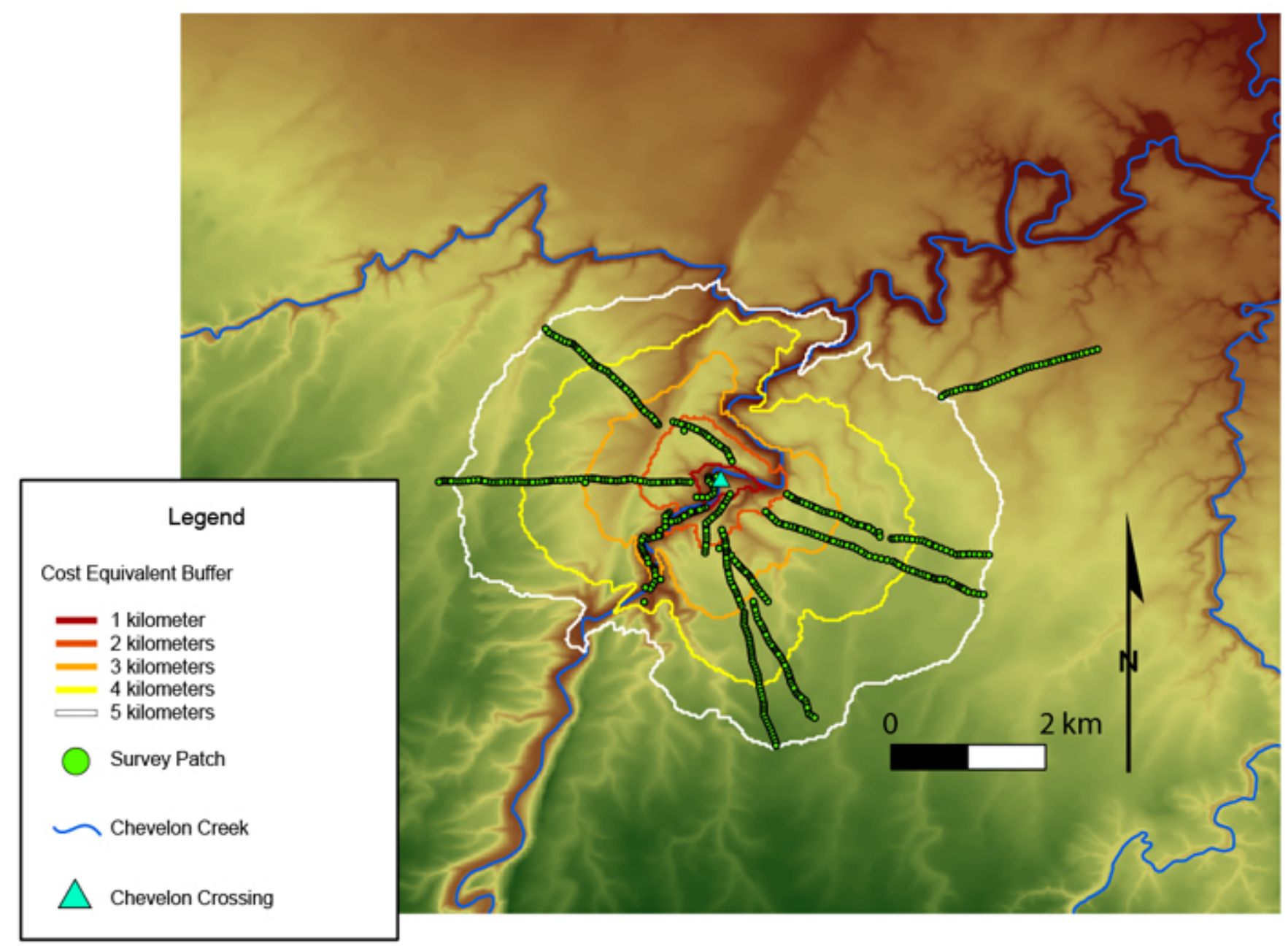

associations that change through time and space between artifact accumulations and landscape characteristics. Table 1 shows the chronological framework, based on analysis of the ceramic and lithic materials recovered in each transect, that we apply to the study area and use in the discussion below.

\section{Preagricultural and transitional agricultural subsistence > 9000 B.C.-A.D. 400}

Although artifacts associated with both the preagricultural and transitional periods were recovered, these periods are difficult to differentiate due to overlapping temporal distributions of diagnostic artifacts. Distinguishing artifacts of this early period from the subsequent agricultural periods is more reliable. One way to do this systematically at landscape scales is to calculate the ratios of stone artifacts to ceramic sherds. High lithic to ceramic ratios indicate residues of primarily Archaic or early agricultural use. In $88 \%$ of the patches with chronologically sensitive projectile points and relatively high lithic to ceramic artifact ratios (> 5:1), the projectile points were associated with the Archaic or Basketmaker periods.

As Figs. $4 a$ and $4 b$ show, collection patches with high lithic to ceramic ratios are primarily found in the canyon bottomlands, terraces, and uplands 
Table 1. Chronology of the Middle Chevelon Creek study area.

\begin{tabular}{lll}
\hline \hline Subsistence & Period & Calendar Dates \\
\hline Preagricultural & Archaic & $>9000$ B.C., 7-1000 B.C. \\
Transitional & Late Archaic/Early Basketmaker & 1000 B.C.-A.D. 400 \\
Agricultural & Basketmaker II/III & A.D. $400-700$ \\
& Pueblo I-Early Pueblo II & A.D. $700-1030$ \\
& Late Pueblo II-Pueblo III & A.D. $1030-1300$ \\
\hline
\end{tabular}

within $1 \mathrm{~km}$ of Chevelon and West Chevelon Creeks, indicating more intensive use of landscapes in and bordering the major canyons than other areas in this period. These canyon corridors are geomorphologically unstable locations. Snowmelt and runoff from the Mogollon Rim is diverted into narrow canyons where periodic floods can scour and erode terraces, uproot vegetation, and deposit new sand and gravel bars. This geomorphic instability both destroys some potential subsistence resources and creates new opportunities for exploitation. Historic records of the first Anglo-American settlers in the region indicate that substantial floods along Silver Creek to the east destroyed irrigation canals on the average once every $5 \mathrm{yr}$, indicating the frequency of these major flooding events (Lightfoot and Plog 1984).

Paleoenvironmental data suggest that Chevelon Creek developed into a sizable perennial stream prior to the Late Archaic period. Although there has been a long-term trend toward increasing aridity since the mid-Holocene in this region, pollen evidence suggests that the most significant Holocene climatic changes took place prior to about 1000 B.C. (Briuer 1977). Hence, the hydrological regime that characterizes Chevelon Creek today, and drives the temporal dynamics in ecological communities in the canyon corridor, would have been in place well-before the initial appearance of agriculture there.

An important consequence of spatial and temporal variability in flooding events is the creation of a series of different microenvironments along the canyon, and high biodiversity at the scale of the canyon corridor landscape as a whole. As particular areas are destroyed by floods, chaotically redistributing biomass previously stored in mature forest and woodlands, other areas are populated by pioneer species with edible fruits, roots, and shoots, and still other areas, yet unaffected by canyon floods, remain covered with mature stands of conifer and hardwoods. The result is a temporally shifting mosaic environment in which different places are characterized by different resources at different times. No single resource is predictably available at any particular location, nor is any location predictably reliable for subsistence needs over the long term. The use of such an environment likely promoted flexibility as well as limited investment in any one particular place or resource (e.g., Wills 1988, Matson 1991, Wills 1995).

Domesticates were probably initially incorporated into this subsistence system and used in much the same way as wild resources. Early strains of maize entered the area sometime between 1000 B.C. and A.D. 1 (Adams 1994), but it is unlikely that subtropical grasses would have been a dependable resource in the frost-prone Mogollon highlands (Matson 1991). It has been suggested that early domesticates may have been planted by foragers as part of their seasonal rounds in an attempt to increase the availability of diverse resources throughout the year (Matson 1991, Wills 1995). This would have been especially effective in flood-disturbed areas of canyon corridors, where planted maize would behave like other pioneering species. 
Fig. 4. (A) Lithic to ceramic weight (g) ratios for all survey patches. (B) Histogram of lithic counts against distance from the canyon. (C) Histogram of ceramic weights in grams against distance from the canyon.

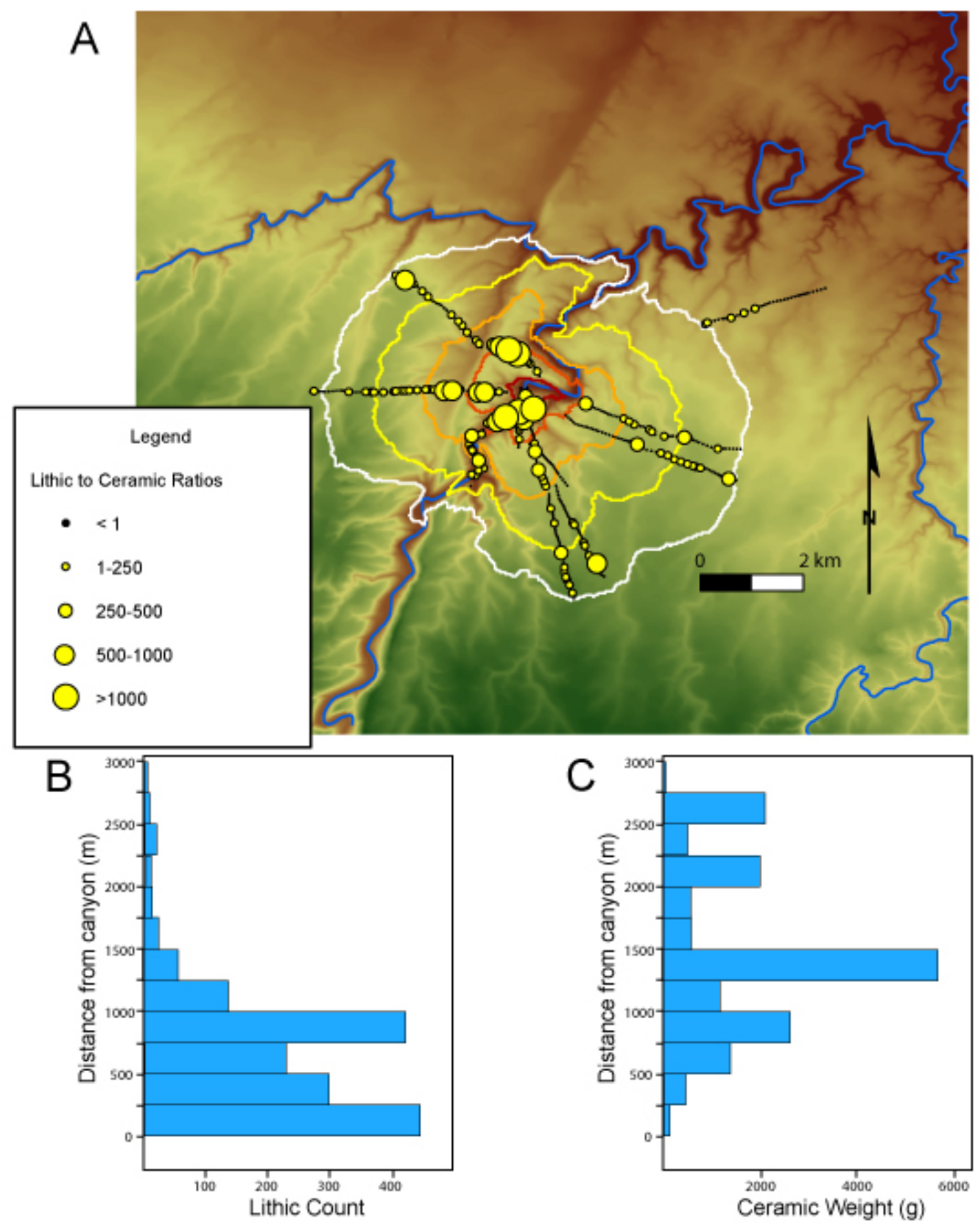


Results of excavations at Chevelon Crossing provide additional evidence of the flexible nature of the subsistence system. Charcoal and seeds recovered during excavations showed that inhabitants used a wide variety of wild plants. Maize (Zea maize) pollen was recorded in 4 out of 32 analyzed auger core samples from this site and one possible cupule was recovered, confirming the presence of early domesticates. Excavations based on the results of the coring program located several pithouses, metates, i.e., grinding stones, and a slablined cyst capped with a metate. The metates were simple basin metates with little use wear. The pithouses were ephemeral structures with only shallow depressions and little architectural investment. The capped cyst contained pinyon nutshells suggesting that inhabitants of this area still relied on wild foods. Taken together, this evidence suggests a subsistence strategy that relied on a diversity of resources invested minimal time or labor in any one resource or the construction of permanent structures in this single locality (Schmich et al., unpublished manuscript).

Resilience theory (RT) offers a conceptual framework in which to characterize the coupled time-space dynamics of the environment and subsistence system of Late Archaic foragers and early agriculturalists in this region. The canyon bottom landscapes heavily used by early inhabitants of the region offered a variety of resources. Ecological cycles were driven by climatically induced flood events caused by snowmelt and rain to the south along the Mogollon Rim, which modified the local environments surrounding Chevelon Creek. Floods destroyed some areas, i.e., $\Omega$-phase, and reconfigured others, i.e., $\alpha$-phase, producing new exploitable niches for plants and animals to colonize, i.e., $r$ phase, and build up biomass, i.e., $\mathrm{K}$ phase. Due to the frequency of flooding, long conservation phases were probably rare in the canyon bottom communities at any one place. Additionally, cycles were out of phase in different canyons or even different segments of the same canyon corridor. Artifact accumulations within the study area suggest that these active canyon landscapes were the areas most heavily utilized by humans in this period. Excavations at the Chevelon Crossing site illustrate that the inhabitants of this area used a diversity of resources, both wild and domesticated, while not investing significant time or labor in any one place or resource. This suggests that short term, high frequency ecological cycles occurred within human life spans, and subsistence strategies adjusted to these cycles. Humans could exploit a diverse subsistence base by shifting settlements to areas recently affected by $\Omega$ phase release.

In RT terms, the human system was resilient in that its fundamental organization remained unaltered in the face of high-frequency $\Omega$-phase events like canyon floods in their local environments. Rather, humans tracked such disturbance events and harvested the abundant resources they made available, primarily from rapidly growing r-phase pioneer species, but also hunting larger animals such as deer and elk that also were attracted to the richer consumable resources of $r$-phase landscape patches. Humans also used the upland woodland K-phase resources, primarily pine nuts. These are abundant, though their availability varies spatially from year to year like r-phase resources in the canyon bottoms. This further promoted settlement mobility and limited labor investment in any particular place. The result was dynamic stability on the part of humans, the long-term maintenance of the overall subsistence system by taking advantage of shortterm ecological cycles in canyons and spatially variable resource availability in the uplands.

Local activities were also affected by lowfrequency, large-scale processes. The general trend toward increasing aridity in the region, occurring over millennia, opened up the heavily vegetated banks of Chevelon Creek making this seasonal stream a perennial watercourse by about 1000 B.C. (Briuer 1977). More importantly for human subsistence economics, genetic changes in corn and its gradual diffusion from Mexico to the Colorado Plateau allowed this domesticate to be incorporated into the diet of Late Archaic foragers between 1000 B.C. and A.D. 1 (Adams 1994). From an RT perspective, these were cross-scale linkages that differentially affected the long-term character of the foraging and early agricultural subsistence system. Below, we examine the consequences of these changes taking place at different temporal and spatial scales on the socioecology of the Chevelon Crossing region.

\section{Prehistoric agricultural subsistence, A.D. 400_ 1300}

The transition from foraging and early agriculture to a subsistence system heavily dependant on agricultural foods in the Chevelon Crossing region 
is not currently well understood or well dated. The numerous arguments relating to the processes involved of this shift in strategies (Wills 1988, Matson 1991, Wills 1995) are beyond the scope of the current paper, but a few comments can be made based on the existing evidence. The earliest maize agriculture in the Mogollon Highlands has been dated conservatively to somewhere between 1000 B.C. and A.D. 1 (Adams 1994). However, it is unlikely that earliest strains of maize would have been very productive in the frost-prone Mogollon Highlands (Matson 1991). Later varieties, however, thrived throughout the Colorado Plateau. Evidence from the more than 30,000 prehistoric maize cobs recovered from Tularosa Cave in the highlands of western New Mexico suggests that there was a rapid change in the row numbers per cob occurring around A.D. 500-700, likely linked with the infusion of a new variety of maize, Mais de ocho (Cutler 1952, Adams 1994). Shifts in the genetic characteristics of maize varieties available also allowed this domesticate to be cultivated more reliably in the short growing season of the Colorado Plateau uplands. This genetic change is correlated with evidence for increasing reliance on agricultural foods in this area (Adams 1994).

The beginning of the agricultural period in the Chevelon Crossing region is marked by the presence of ceramic containers and masonry structures, although pit structures were still constructed and occupied. Decorated and plainware ceramic sherds were used as the basis for the chronological assignment of collection units within this period. As Figs. $4 a$ and $4 c$ show, there is a major shift in the portions of the landscape most heavily utilized by agriculturalists in this period, compared to the previously discussed Archaic/transitional periods. High ceramic densities and structures, both masonry and pithouses, are primarily found on the sandy upland soils of the ecologically more stable and less diverse pinyon-juniper woodland, more than $1 \mathrm{~km}$ away from major streams and the dynamic canyon bottomlands (Figs. 4 and 5).

Agricultural settlements in they study area are small, < 3 rooms, with little associated trash (McAllister et al. 1978). Although excavations would be necessary to estimate the occupation lengths of individual settlements more accurately, the lack of substantial trash suggests that each settlement and surrounding areas of the landscape were not occupied intensively or for very long periods. Datable ceramic materials also suggest that the areas around these settlements were not occupied for long periods, nor were they subsequently reoccupied after initial abandonment.

Within the study area, an examination of the total extent and total weights of ceramic materials relating to each subperiod shows a marked increase of these artifactual residues of human activity during the period around A.D. 1030-1300, suggesting increasing use of the upland areas of the landscape at this time. This increase coincides with a noted influx of population to the larger middle Chevelon region, and the Colorado Plateau in general, occurring around approximately A.D. 1000-1150 (Dean et al. 1985). Ceramic evidence suggests that this particular portion of the study area was not heavily utilized after the late 13th Century.

There has been much debate regarding the nature of prehistoric agriculture on the Colorado Plateau and the Mogollon Rim. Some of this debate stems from the fact that the forested upland areas along the Colorado Plateau and the Mogollon Highlands, where Chevelon Creek is located, are significantly different environments than the areas currently occupied by the modern western Pueblos, Hopi mesas, and Zuni River Valley. This has led some to believe that reconstructions of agricultural practices based on ethnographic data from modern Pueblo farmers are likely inaccurate (Sullivan 1982).

Based on paleobotanical and settlement pattern data, several researchers have postulated that the prehistoric agricultural system in the Mogollon Highlands, and more generally along the Colorado Plateau, may have been based on a type of shifting cultivation no longer practiced by Puebloan farmers (Wilcox 1978, Stiger 1979, Sullivan 1982, Kohler and Matthews 1988, Kohler 1992a,b, Varien 1999). As proposed for the Colorado Plateau, this involves clearing trees with fire, followed by planting in these cleared areas until the initially high yields decline. Matson et al. (1988) note that on the Colorado Plateau, dense stands of pinyon and juniper are frequently associated with deeper aeolian soils with significantly higher nutrient levels, i.e., 2-20 times greater, than open woodland areas or shrub flats. In addition to this, experimental studies suggest that clearing dense stands of coniferous trees by burning individual trees involves much less labor than clearing shrub vegetation without metal tools (Matson et al. 1988). It probably would not have been necessary for massive plots of forest to be cleared such that wood resources were locally 
Fig. 5. Locations of structures within survey transects.

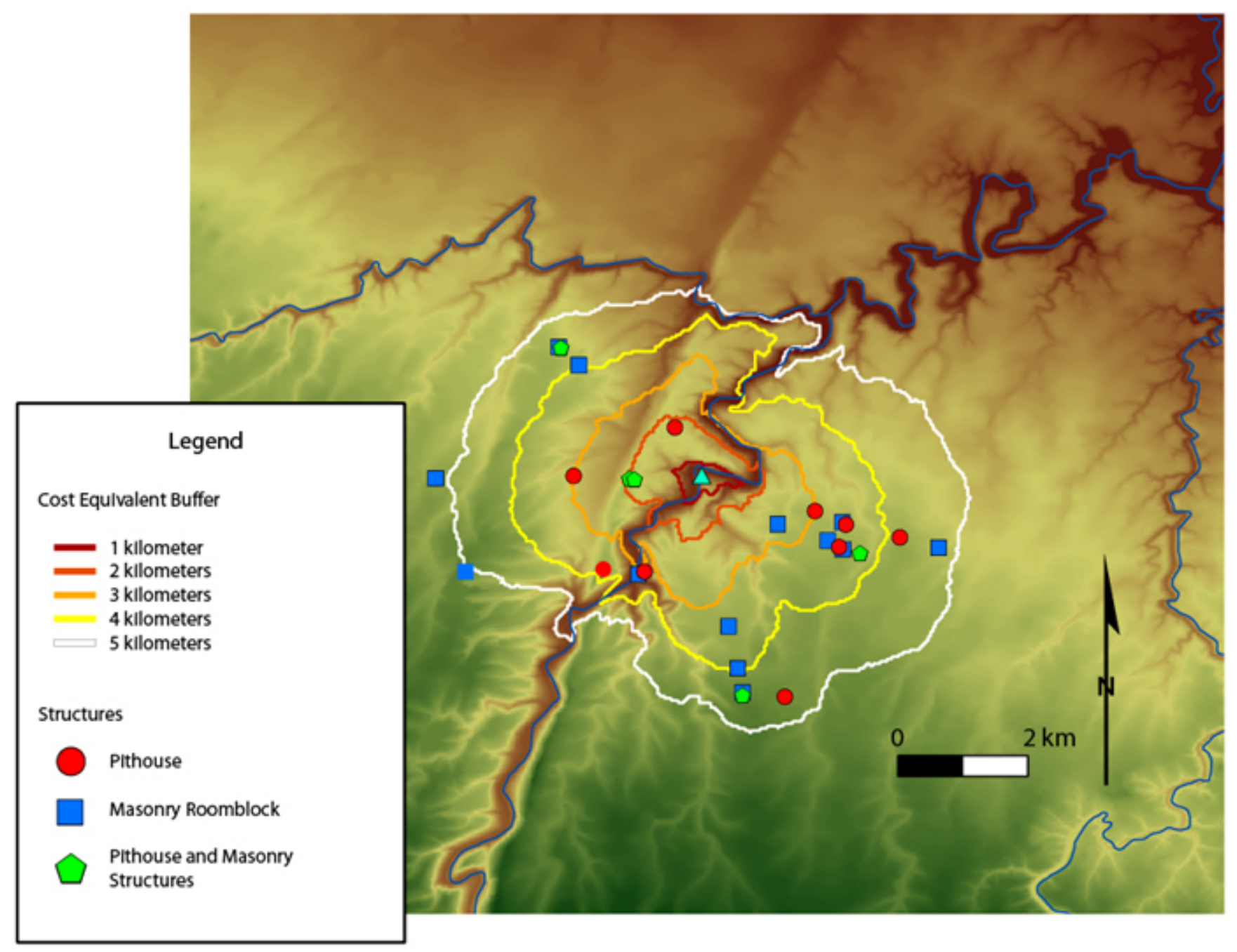

depleted, although there is evidence of this in certain portions of the Colorado Plateau (Kohler and Matthews 1988). However, the clearance of small, dispersed fields over time likely could have opened the forest canopy significantly. Such a system of shifting cultivation is not, however, without costs. Regrowth of the pinyon/juniper woodland can take centuries following clearance, and removal of vegetation with such a slow rate of regeneration may have led to soil loss in field locations (Kohler and Matthews 1988). Decreasing yields due to nutrient or soil loss at the level of the field likely would have prompted regular residential mobility on a supraannual basis (e.g., Varien 1999).
In an environment such as the sparsely occupied Chevelon Crossing region, where there was an initial abundance of land and a lack of significant labor capital, such a strategy would have been highly advantageous. The settlement pattern in the Chevelon Crossing survey area seems to support this strategy as well. Occupation was land extensive throughout the region with little evidence of agricultural intensification, i.e., terraces, water control features, etc., until late, post 1100 in the occupation sequence (Dean et al. 1985, Lightfoot and Plog 1985). Though further research would be necessary to clarify this issue, shifting cultivation seems to be a likely agricultural strategy for the early 
prehistoric farmers in the Chevelon Crossing region. In terms of people supported per unit of land, this strategy was probably more productive than earlier foraging, even combined with casual canyon-bottom gardens. It certainly produced a great deal more in the way of artifactual residues in a much shorter time. However, it also was sustainable for a shorter time than the preceding socioecological system. As we discuss below, the apparent lack of reoccupation of agricultural settlements within the study area may be due, in part, to the extremely long period required for vegetation and nutrients to regenerate.

As farmers depended on agricultural resources for a majority of their dietary needs, crop failures would have been increasingly more difficult to overcome. Although population levels were relatively low in the region, farmers could buffer agricultural shortfalls by supplementing their diets with wild resources (Huckell 1999). As population levels increased in the region after A.D. 1000, however, a lengthening land use history of shifting cultivation, coupled with long regeneration times would have limited the availability of the most abundant edible $\mathrm{K}$-phase resource near settlements in the pinyonjuniper woodlands. Along with the population increase, the first evidence for agricultural intensification in the form of water and soil control features appears, as increasing population limited options for diversifying the subsistence base and promoted technological responses to declining productivity. This suggests that both the population level, i.e., human capital, and the productivity, i.e., technological and landesque capital, of the subsistence system play important roles in the resilience of socioecological systems that need to be considered.

Another response to agricultural shortfalls is the development of social connections via exchange relationships. Although it is difficult to measure the amount of exchange taking place, ceramic evidence from the study area suggests that farmers did have ties to the inhabitants of more distant regions. Maintaining connections to ecologically diverse regions gave the inhabitants of the Chevelon Crossing region another way to buffer resource shortfalls within the local environment. Toward the end of occupation in this region, however, the low spatial variability of rainfall over the entire northern southwest (Dean et al. 1985) may have limited the utility of exchange as a response to resource requirements.

\section{The transition to agriculture in a resilience theory framework}

RT provides a useful framework in which to compare the dynamics of what appear to have been two very different socioecological systems: that of earlier Archaic foragers and transitional agriculturalists, and that of later agriculturalists. Previously, we characterized the earlier system as tracking and exploiting $\mathrm{r}$-phase resources in canyons made available by naturally driven $\Omega$ release cycles, primarily frequent floods. They also tracked abundant, though spatially variable, low-diversity $\mathrm{K}$-phase resources of the upland pinyon-juniper woodland.

In RT terms, later agriculturalists followed much the same strategy, basing their subsistence on $r$ phase resources, but doing so in a different socioecological context. Intentional, anthropogenic fire, for land clearance-initiated $\Omega$ release cycles, whereas domesticated annuals such as maize, beans, and squash were the r-phase colonizers of the human-disturbed landscape. The fact that the woodlands were fired after several centuries of growth meant that considerable quantities of nutrients were released into the soils that had accumulated under the trees, making the r-phase gardens highly productive in terms of edible resources. Human control of $\Omega$ events and r-phase cultigens also made the availability of these resources spatially predictable. The productivity and predictability would have made shifting an $\mathrm{r}$ phase resource exploitation strategy from canyon bottoms to the upland pinyon-juniper woodlands a very attractive proposition, and one whose results in terms of human settlement are borne out in the archaeological record, both in terms of the evidence for population increase and the distribution of settlements.

Along with the higher productivity for the people of the Chevelon Crossing region, shifting their $r$ phase resource exploitation strategy from the canyons to the uplands also had unforeseen longerterm consequences on the Colorado Plateau that stand out when viewed from an RT perspective. First, the communities of the canyons and the uplands are driven by different processes and cycle at very different temporal scales. The canyon $\Omega$ events are dominated by floods and happen at subdecadal frequencies. The floods bring a rich nutrient supply, i.e., organic-rich alluvial sediments and uprooted plants, with each release. With 
regularly enriched soils and ample water, plants grow rapidly, accumulating biomass and cycling from $r$ to $K$ phases.

In the absence of human intervention, the upland ecosystem cycles over much longer time frames, with release through regeneration phases occurring over a span of centuries. Nutrients accumulate autochthonously in the form of needle duff and leaf litter, and are released when a tree dies due to fire, disease, or old age. Lacking redeposited alluvium, upland ecosystems mainly recycle nutrients present in each landscape patch. Human initiated $\Omega$ events release a rich nutrient supply, but one that is only replenished across centurial time scales. The released nutrients that were captured by efficient domestic r-phase plants and consumed by humans were not available for woodland regrowth, however, retarding this already long cycle. Furthermore, vegetation removal and cultivation would have left the thinner soils of the upland areas more vulnerable to erosion and nutrient loss from increasing runoff and leaching (e.g., Kohler and Matthews 1988, Sandor et al. 1991). Finally, this combination of factors, along with ever-changing climatic conditions in the southwest, could well have changed the ecological context for upland plant communities such that, as RT theorists observe, the pinyon-juniper woodland may not have returned to its preagricultural configuration. Notably, the thin and rocky soils that characterize the study area today have not been cultivated since prehistoric farmers abandoned it over $700 \mathrm{yr}$ ago.

Canyon bottom ecosystems appear to have been resilient to high-frequency, flood-generated perturbations, and cycled at roughly the same or shorter temporal scale as human generations. This meant that r-phase resources were probably available to be harvested by humans somewhere within the Chevelon Crossing region more or less continually. Upland systems, on the other hand, cycled at the scale of multiple human generations, and an r-phase resource exploitation strategy could only be sustained by continuously initiating release events on new patches of K-phase woodland. The archaeological record of this land use strategy in the Chevelon Crossing region appears in the form of regularly spaced settlements, created as farmers repeatedly moved to clear and cultivate a fresh patch of land and avoided previously farmed patches that had entered an $\alpha$-phase ecological reorganization and long period of woodland regrowth that left them agriculturally unproductive for generations.
There is another significant difference in the context and consequences of humans shifting an r-phase exploitation pattern from the canyon bottoms to the uplands. Archaic foragers and transitional agriculturalists used both r-phase resources of the canyons and K-phase resources from the uplands. Pinyon nuts especially, from the K-phase woodlands, made an important contribution to the earlier subsistence strategy. Because the canyon and upland ecosystems operated at very different temporal scales and were spatially distinct, these two kinds of resource use were generally complementary. This also meant that the two ecosystems were also generally out of phase so that potentially disastrous, simultaneous resource shortfalls in both were rare. However, when humans shifted to upland agriculture, replacing the use of plants in flood-disturbed canyon bottoms with cultigens, exploitation of r-phase and K-phase resources became competitive. Initiating an $\Omega$ event to release nutrients for $r$-phase cultigens required destruction of the source of K-phase resources. Furthermore, as Flannery (1986) notes, time spent cultivating r-phase resources in the uplands was time not available for collecting r-phase resources in the canyons. This left agriculturalists increasingly at risk in the case of crop failures.

Initially, agriculturalists in the region successfully mitigated the risks associated with their local land use practices through supra-annual movement. With the population growth noted in the archaeological record after A.D. 1000, however, potentially productive land would have become increasingly scarce. It is in this later agricultural period that the earliest evidence for intensification occurs, with investment in landesque capital in the form of terraces, check dams, and other measures that limit water and soil loss. Although this may have extended the productive potential of a landscape patch, it also increased farmers' investment in particular places, making moves more costly when conditions eventually became untenable.

Cross-scale interactions also differentially affected the human socioecosystems in the Chevelon Crossing area over time. Certainly, low-frequency climatic cycles must have affected the abundance of both r-phase and K-phase resources for Archaic foragers. However, the archaeological record shows a history of human occupation without notable change in settlement organization extending for millennia prior to $\mathrm{AD} 400$. The initial appearance 
of maize also seemed to have had minimal impacts. In this sense, the human system appears to have been resilient in the ecological sense that it maintained its overall function and organization across perturbations at varying spatial and temporal scales.

Human induced genetic changes in maize had more profound effects, initiating the relocation of the human subsistence system to the pinyon-juniper woodlands. Though different from Holling's original formulation, this transition to upland agriculture can be viewed as a human socioecological equivalent of an $\alpha$-phase reorganization (e.g., sensu Redman and Kinzig 2003), but one that lacks a catastrophic release of natural capital or phase change from order to disorder. That is, although humans still relied on $\mathrm{r}-$ phase resources, they began to manage both the $\Omega$ phase and $r$ phase of the upland adaptive cycle, and they did so at the expense of complementary Kphase resources. Human settlement mobility decreased, population increased, and material culture altered significantly. Although people still depended, perhaps even more than previously, on r-phase resources, agriculture represents a fundamental change in the way they were managed and harvested.

This reorganization also seems to have left humans more vulnerable to cross-scale effects. Many of the later occupation sites in the region were positioned in what have been described as defensive locations, suggesting that social conflict may have been escalating (Plog et al. 1976), restricting access to declining and spatially shifting wild resources, and favoring more defensible agricultural fields. A 25yr period of decreased precipitation, i.e., "the great drought," occurred from approximately A.D. 1275 to 1300 , and was marked by low water tables, low precipitation, and arroyo down cutting (Euler et al. 1979, Dean et al. 1985). Although earlier populations seem to have weathered variations in precipitation that are characteristic of this region over the long-term, the 13th Century "drought" would have had a much greater impact on r-phase resources, i.e., cultigens, in drier uplands than in wetter canyon bottoms. It would also have simultaneously lowered the productivity of remnant pinyon groves, at a time when their spatial extent had been reduced by agricultural clearance. The synchronized stress on r-phase and K-phase resources came at a time of social stresses from increasingly dense population and declining fertility of the land. By ca. 1300, this combination of social and natural processes had set off a cascade of socioecological changes that may have triggered an ecological reorganization of the pinyon-juniper woodland and certainly resulted in the human abandonment of the Chevelon Crossing region for centuries.

\section{CONCLUSION}

As the previous discussion suggests, using resilience theory (RT) concepts as a guides thinking about change in this complex socioecological system has a number of advantages. RT encourages us to think explicitly about the dynamics of past systems rather than their states at different time intervals, and provides a vocabulary designed for this. It also promotes an explicit examination of interactions among system components and with other systems at multiple spatial and temporal scales. As the data from the Chevelon Crossing area suggests, changes in socioecological systems are linked at a number of spatial and temporal scales. Variations in weather, regional demography, and the genetic makeup of domesticates can have tangible effects at a local level. The individual decisions of prehistoric farmers on where to plant, what land to clear, and when to move can affect both the physical characteristics of the landscape as well as the social contexts of subsistence activities, possibly fostering changes in larger processes.

The concept of the adaptive cycle is beneficial because it emphasizes the multiple possible trajectories for growth and development. Additionally, RT suggests that social and ecological systems are adaptive but that adaptation can change system dynamics and require new adaptations; therefore change and stability are both inevitable. The addition of the $\alpha$ or reorganization phase into considerations of adaptive systems is useful in describing the processes through which systems fundamentally change or resist change. RT perspectives focus analysis on the reorganization of social systems. Much archaeological research has focused on "collapse" with little acknowledgement or consideration of subsequent reorganizations and how they were structured. RT is a useful perspective specifically because it directs research toward this frequently overlooked aspect of the archaeological record (Redman and Kinzig 2003, Redman 2005).

The RT conceptual framework also makes it easier to compare the dynamics of apparently disparate 
systems, like the preagricultural and agricultural socioeconomies in the Chevelon Crossing region. Such conceptual tools are of considerable value in archaeology, which is continually faced with the need to model, qualitatively or quantitatively, the dynamics of past human systems from the static archaeological record. In the Chevelon Crossing region, RT has helped us highlight economic continuity in emphasis on r-phase resources between pre-agricultural and agricultural peoples, and the consequences of following this subsistence strategy in differing socioecological contexts.

Although RT provides a useful conceptual framework for characterizing prehistoric dynamics, it does not of itself offer explanatory theory that accounts for why the prehistoric humans in the Chevelon Crossing region shifted subsistence focus from the canyons to the uplands, why the socioecosystems interacted differently with the landscape, or why they had different consequences. However, using RT concepts to describe these systems and their dynamics in comparable ways has helped us to generate hypotheses that do attempt to explain some of these phenomena and begin to test them.

Although RT provides a consistent conceptual framework and vocabulary that can be applied to many kinds of complex systems, systems may not necessarily need to pass through all four phases of the adaptive cycle as originally proposed by Hollings and others. In the Chevelon Creek case, for instance, the socioecological shift from foraging to agriculture has all the appearances of an $\alpha$-phase reorganization of the subsistence system. However, this reorganization was not preceded by an $\Omega$ phase release, as generally portrayed in the RT literature, but most likely triggered by cumulative genetic changes in maize that took place over the course of a millennium or more. These small, slow changes passed a threshold that made upland maize agriculture potentially more productive than canyon-bottom foraging. A simplistic attempt to force the socioecology of the Chevelon Crossing region into strictly defined four phases of the adaptive cycle would obscure important aspects of its dynamics. This suggests that it may be worthwhile to rethink the particular definitions of the cycle, while maintaining the fundamental concepts when extending it to human systems. For example, an $\Omega$ event might be more broadly thought of as a threshold event that initiates reorganization and which may, or may not, be the result of a sudden entropic release of stored biomass.

Finally, this study raises provocative questions about the nature of resilience and sustainability, success, and failure. It is easy to call Archaic foragers resilient when they maintained for millennia a way of life focused on harvesting $r$ phase resources in canyons. However, this way of life broke down rapidly in the face of genetic changes in maize, one of the resources they came to use, even though they did not appear to depend on it in a major way. Was this a failure? The people of this region maintained a dependence on r-phase resources across the change from foraging to farming. Was this resilient? It is also easy to claim that the agricultural socioecosystem of the Chevelon Crossing region was unsustainable, the farmers were not resilient, and their practices led to failure. However, they managed to prosper using shifting cultivation in this agriculturally marginal area for over $800 \mathrm{yr}$, during which they surely faced numerous social and environmental challenges. Is this really an example of unsustainable practices and an inflexible society on its way to destruction? The agricultural socioecology of the Chevelon Crossing area lasted for centuries, compared with the millennia of the preagricultural system, but supported more people. Which system was more successful?

Applying RT in archaeological research offers new insights to our understanding of past human systems. Examples such as the Chevelon Crossing case can help resilience theorists better understand potential driving factors for changes in other systems, including modern land use. Even more importantly, expressing the ecological history of the prehistoric inhabitants of middle Chevelon Creek in a more general theoretical language that bridges the social and natural sciences has larger potential benefits. Such a common language promotes the collaboration of scientists with expertise deriving from different traditional disciplines that is needed to understand complex socioecological systems. Further, it provides a framework in which explicit explanatory models can be developed for such systems, using concepts integrated from these multiple knowledge domains, and evaluated in the laboratory of the long and diverse archaeological record. We see this kind of approach as increasingly important in the future of archaeology and in the sciences of human society more generally. 
Responses to this article can be read online at:

http://www.ecologyandsociety.org/voll1/iss2/art22/responses/

\section{Acknowledgments:}

The Mogollon Rim Small-site Survey (MRSS) project is directed by Michael Barton and Margaret MacMinn-Barton of the School of Human Evolution and Social Change at Arizona State University. The authors gratefully acknowledge support for this work from the National Science Foundation Biocomplexity program (Grant \#BCS-0508001). In addition, this research has been supported in part by Apache-Sitgreaves National Forest, the University of Valencia, the Graduate Research Support Program at Arizona State University, and the Archaeological Research Institute at Arizona State University. We would like to thank Jeremy Haines, Hamed Vahdatinasab, Charlotte Hunter, and Linda Martin from the U.S. Forest Service for sharing archaeological site information, providing data in GIS format, and for logistical support. We would also like to thank Julien Riel-Salvatore for initially compiling the GIS databases. Melissa Kruse provided her GIS expertise in the preparation of the maps used here. We also owe a large debt of gratitude to Peggy Nelson, Marty Anderies, and Sander van der Leeuw for their support with this project.

\section{LITERATURE CITED}

Adams, K. R. 1994. A regional synthesis of Zea mays in the prehistoric American Southwest. Pages 273-302 in S. Johannessen and C. A. Hastorf, editors. Corn and culture in the prehistoric New World. Westview, Boulder, Colorado, USA.

Barton, C. M., J. B. Auban, J. E. Aura Tortosa, O. Garcia, and N. La Roca. 2002. Dynamic landscapes, artifact taphonomy, and landuse modeling in the western Mediterranean. Geoarchaeology 17:155-190.

Barton, C. M., J. B. Auban, O. G. Puchol, S. Schmich, and L. Molina Balaguer. 2004. Longterm socioecology and contingent landscapes. Journal of Archaeological Method and Theory 11:253-295.
Braudel, F. 1980. On history. University of Chicago Press, Chicago, Illinois, USA.

Briuer, F. L. 1977. Plant and animal remains from caves and rock shelters of Chevelon Canyon Arizona: methods for isolating cultural deposition processes. Dissertation. University of California, Los Angeles, California, USA.

Butzer, K. W. 1982. Archaeology as human ecology. Cambridge University Press, Cambridge, UK.

Butzer, K. W. 1996. Ecology in the long view: settlement histories, agrosystemic strategies, and ecological performance. Journal of Field Archaeology 23:141-150.

Cutler, H. C. 1952. A preliminary survey of plant remains of Tularosa Cave. Pages 461-479 in P. S. Martin, J. B. Rinaldo, E. Bluhm, H. Cutler, and R. Grange Jr., editors. Mogollon cultural continuity and change. Fieldiana: anthropology. Volume $\mathbf{4 0 .}$ Field Museum, Chicago, Illinois, USA.

Dean, J. S., R. C. Euler, G. J. Gumerman, F. Plog, R. H. Hevly, and T. N. V. Karlstrom. 1985. Human behavior, demography, and paleoenvironment on the Colorado Plateaus. American Antiquity 50 (3):537-554.

Euler, R. C., G. J. Gumerman, T. N. V. Karlstrom, J. S. Dean, and R. Hevly. 1979. The Colorado Plateaus: cultural dynamics and paleoenvironments. Science 205:1089-1101.

Flannery, K. 1986. Guilá Naquitz: archaic foraging and early agriculture in Oaxaca. Academic Press, New York, New York, USA.

Foster, D., F. Swanson, J. Aber, I. Burke, N. Brokaw, D. Tilman, and A. Knapp. 2003. The importance of land-use legacies to ecology and conservation. BioScience 53(1):77-88.

Gunderson, L. H. 2000. Ecological resilience in theory and application. Annual Review of Ecology and Systematics 31:425-439.

Gunderson, L. H., and C. S. Holling, editors. 2002. Panarchy: understanding transformations in human and natural systems. Island Press, Washington, D.C., USA. 
Hardesty, D. L., and D. D. Fowler. 2000. Archaeology and environmental change. Pages 7289 in C. Crumley, editor. New directions in anthropology and the environment: intersections. Alta Mira, Walnut Creek, California, USA.

Hill, B. 1995. Ecological variability and economic specialization. Thesis. Arizona State University, Tempe, Arizona, USA.

Holling, C. S. 1973. Resilience and stability of ecological systems. Annual Review of Ecology and Systematics 4:1-23.

Holling, C. S., and L. H. Gunderson. 2002. Resilience and adaptive cycles. Pages 25-62 in L. H. Gunderson and C. S. Holling, editors. Panarchy: understanding transformations in human and natural systems. Island Press, Washington, D.C., USA.

Holling, C. S., L. H. Gunderson, and D. Ludwig. 2002. In quest of a theory of adaptive change. Pages 3-24 in L. H. Gunderson and C. S. Holling, editors. Panarchy: understanding transformations in human and natural systems. Island Press, Washington, D. C., USA.

Holling, C. S., L. H. Gunderson and G. D. Peterson. 2002. Sustainability and panarchies. Pages 63-102 in L. H. Gunderson and C. S. Holling, editors. Panarchy: understanding transformations in human and natural systems. Island Press, Washington, D.C., USA.

Kohler, T. A. 1992a. Field houses, villages, and the tragedy of the commons in the early Northern Anasazi Southwest. American Antiquity $\mathbf{5 7}$ (4):617-634.

Kohler, T. A. 1992b. Prehistoric human impact on the environment in the upland North American Southwest. Population and environment: a journal of interdisciplinary studies 13(4):255-268.

Kohler, T. A., and M. H. Matthews. 1988. Longterm Anasazi land use and forest reduction: a case study from southwest Colorado. American Antiquity 53(3):537-564.

Lightfoot, K. G., and F. Plog. 1984. Intensification along the north side of the Mogollon Rim. Pages 179-195 in S. K. Fish and P. R. Fish, editors. Prehistoric agricultural strategies in the Southwest.
Anthropological Research Papers. Volume 33. Arizona State University, Tempe, Arizona, USA.

Matson, R. G. 1991. The origins of southwestern agriculture. University of Arizona Press, Tucson, Arizona, USA.

Matson, R. G., W. D. Lipe, and W. R Haase, IV. 1988. Adaptational continuities and occupational discontinuities: the Cedar Mesa Anasazi. Journal of Field Archaeology 15(3):245-264.

McAllister, S. Powell, and F. Plog. 1978. Small sites in the Chevelon Drainage. Pages 17-23 in A. E. Ward, editor. Limited activity and occupation sites. Center for Anthropological Studies, Albuquerque, New Mexico, USA.

Plog, F. T., J. N. Hill, and D. W. Read. 1976. Chevelon archaeological research project, 19711972: monograph II of the archaeological survey. University of California, San Francisco, California, USA.

Redman, C. L., and A. P. Kinzig. 2003. Resilience of past landscapes: resilience theory, society, and the longue durée. Conservation Ecology 7(1):14. [Online] URL http://www.ecologyandsociety.org/vol7/ iss1/art14/.

Redman, C. L. 2005. Resilience theory in archaeology. American Anthropologist 107(1):70-77.

Sandor, J. A., P. L. Gersper, and J. W. Hawley. 1990. Prehistoric agricultural terraces and soils in the Mimbres Area, New Mexico. World Archaeology 22(1):70-86.

Stiger, M. A. 1979. Mesa Verde subsistence patterns from basketmaker to Pueblo III. The Kiva 44(2-3):133-144.

Stone, G. D. 1996. Settlement ecology: the social and spatial organization of Kofyar agriculture. University of Arizona Press, Tucson, Arizona, USA.

Sullivan, A. P. 1982. Mogollon Agrarian ecology. The Kiva 48(1-2):1-15.

van Andel, T. H., and E. Zanagger. 1990. Landscape stability and destabilization in the prehistory of Greece. Pages 139-157 in S. Bottema, G. Entjes-Nieborg, and W. van Zeist, editors. Man's 
role in the shaping of the eastern Mediterranean landscape. Rotterdam, The Netherlands.

van der Leeuw, S., and C. L. Redman. 2002. Placing archaeology at the center of socio-natural studies. American Antiquity 67(4):597-605.

Varien, M. D. 1999. Sedentism and mobility in a social landscape. University of Arizona Press, Tucson, Arizona, USA.

Walker, B., C. S. Holling, S. R. Carpenter, and A. P. Kinzig. 2004. Resilience, adaptability and transformability in social-ecological systems. Ecology and Society 9(2):5.

Wilcox, D. R. 1978. The theoretical significance of fieldhouses. Pages 25-32 in A. E. Ward, editor. Limited activity and occupation sites. Center for Anthropological Studies, Albuquerque, New Mexico, USA.

Wills, W. H. 1988. Early prehistoric agriculture in the American Southwest. School of American Research Press, Santa Fe, California, USA.

Wills, W. H. 1995. Archaic foraging and the beginning of food production in the American Southwest. Pages 215-242 in T. D. Price and A. B. Gebauer, editors. Last Hunters-First Farmers. School of American Research Press, Santa Fe, California, USA. 